\title{
Effect of re-approximation of the rectus muscles on diastasis recti abdominis at cesarean section - a prospective cross-sectional study
}

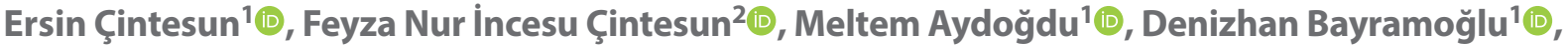 \\ Çetin Çelik ${ }^{1}$ (D) \\ ${ }^{1}$ Department of Obstetrics and Gynecology, Selcuk University Medicine Faculty, Selçuklu, Konya, Turkey \\ ${ }^{2}$ Konya Research and Training Hospital, Meram, Konya, Turkey
}

\begin{abstract}
Objectives: Caesarean section (CS) is one of the most frequently performed surgical procedures in the world and Turkey. In this study, we aimed to investigate the relationship between re-approximation of the rectus muscles during CS and the severity of diastasis recti abdominis in the first postoperative month. To investigate the relationship between re-approximation of the rectus muscles during CS and the severity of diastasis recti abdominis in the first postoperative month.

Material and methods: The study was designed as a prospective cross-sectional study. Patients were divided into two groups: parietal peritoneum closure only (Group 1), and closure of the parietal peritoneum and re-approximation of rectus muscle (Group 2). The distance between the rectus muscles and the thickest rectus muscle thickness were measured one month after CS from three anatomic regions using superficial ultrasonography by the same blinded physician. The anatomic regions were described as xiphoid, $3 \mathrm{~cm}$ above the umbilicus, and $2 \mathrm{~cm}$ below the umbilicus. The relation of the measurements between the groups was evaluated.

Results: There was a total of 128 patients, 64 in Group 1 and 64 in Group 2. There were no statistical differences between the groups in terms of the distance between rectus muscles and the thickness of rectus muscle at the described anatomic regions $(p>0.05)$

Conclusion: Re-approximation of rectus muscles has no effect on the prevention of diastasis recti, which is an important cosmetic problem.
\end{abstract}

Key words: cesarean section; diastasis recti abdominis; parietal peritoneum; umbilicus

Ginekologia Polska 2021; 92, 2: 132-136

\section{INTRODUCTION}

Caesarean section (CS) is an important intervention that provides safe delivery for both mother and baby. CS, defined as the delivery of the foetus through an abdominal and uterine incision, is one of the most frequently performed surgical procedures in the world and Turkey [1-3]. As with most surgical procedures, CS does not have a standard technique. There are many different techniques depending on surgeon preference from the skin to the uterus step. The effort to compare different procedures of CS and find a standard surgical technique has been ongoing for a long time [4-6]. The outcomes of the closure of peritoneum and re-approximation of the rectus muscles have been studied in the literature [7]. In some studies, early parameters such as analgesia dose, postoperative pain, infection, fever, endometritis, and length of hospital stay were investigated, but long-term complications such as diastasis recti abdominis (DRA) have not yet been investigated [7-10]. DRA is defined as the right and left rectus abdominal muscles being abnormally separated from each other at the level of the linea alba. There is no clear cut-off value associated with the inter-rectus distance used in the diagnosis of DRA [11, 12]. DRA can be caused by elevated intra-abdominal pressure, such as pregnancy and obesity. During pregnancy, DRA occurs physiologically and in some patients, it may reduce after birth, whereas in other patients, it either progresses or stays the same. Advanced age, multiparity, cesarean section history, high weight gain - especially after birth - and ethnicity have been defined as risk factors for DRA $[13,14]$. There are many qualitative classification methods for DRA. In these classification methods, the width is taken at three reference points (xiphoid, $3 \mathrm{~cm}$ above the umbilicus, and $2 \mathrm{~cm}$ below 
the umblicus) $[12,15]$, and other classifications take into account myofacial deformity [16]. In addition, studies have shown that the inter-rectus distance of women in postpartum is significantly higher than in nulliparous women up to 12 months after birth [17]. The relationship between rectus abdominis re-approximation, which is a step in CS surgery, and DRA after birth has not been investigated previously.

In this study, we aimed to investigate the relation between re-approximation of the rectus muscles during CS with DRA in the first postoperative month.

\section{MATERIAL AND METHODS}

The study was designed as a prospective cross-sectional study between June 2019 to August 2020 in patients who underwent CS at Selcuk University Hospital. This study was conducted on patients who had a standard CS in our clinic and who were eligible for the study. The patients were divided into two groups according to the closure of the anterior abdominal wall.

Each patient was assigned to one of these two groups: Group 1: parietal peritoneum closure only. Group 2: closure of the parietal peritoneum and re-approximation of the rectus muscle.

Patients with a known skeletal, muscular or systemic disease, patients with preterm pregnancies, very weak patients [body mass index $(\mathrm{BMI})<18 \mathrm{~kg} / \mathrm{m}^{2}$ ], overweight patients $\left(\mathrm{BMI}>30 \mathrm{~kg} / \mathrm{m}^{2}\right)$, multiple pregnancies, multigravid patients, patients with previous abdominal surgery or rectus abdominis muscle surgery, and patients outside the age range of 18-35 years were excluded from the study.

Sixty-four patients who underwent primary CS for various reasons were enrolled in the study. Approval from the institutional local ethics committee was obtained and each patient gave signed informed consent for their participation in the study (Reg. No. 2019/022). The physician performing the ultrasonographic measurement was blinded.

Inter-rectus distance was measured in the first postoperative month. The distance between rectus muscles and the thickest rectus muscle thickness were measured from three anatomic regions using superficial ultrasonography by the same blinded physician. The anatomic regions were described as xiphoid, $3 \mathrm{~cm}$ above the umbilicus, and $2 \mathrm{~cm}$ below the umbilicus. The relation of measurements between the groups was evaluated (Fig. 1).

\section{Surgical procedure}

In our clinic, CS is performed as described below as standard except for the rectus and peritoneum steps. Most CS are performed under regional anesthesia. All women have a Pfannenstiel-type transverse incision. The subcutaneous tissue layer is dissected using the fingers and then a small transverse incision is made medially with a scalpel

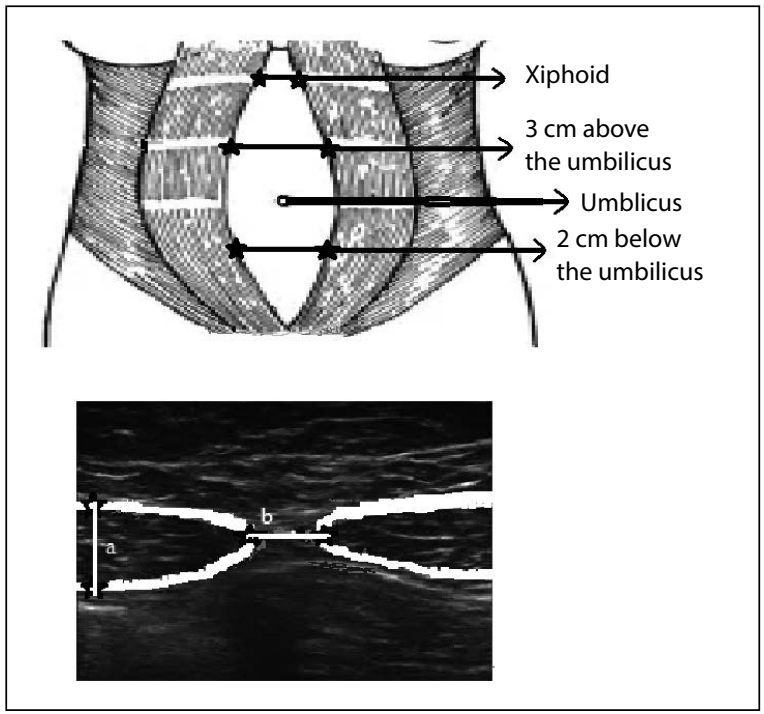

Figure 1. Schematic drawing of the anterior abdominal wall reference points and ultrasonographic measurement of inter-rectus distance and rectus thickness

and extended laterally using scissors in the fascial layer. Rectus muscles are separated bluntly. The peritoneum is opened with the forefinger. A bladder flap is formed, and a low transverse incision is made in the uterus. The uterine incision is closed using a single-layer continuous locked suture with a Vicryl 1.0 suture (Ethicon Johnson \& Johnson, USA). The abdominal cavity is cleaned from amniotic fluid and blood. The parietal peritoneum is closed using a continuous Vicryl 2.0 suture (Ethicon Johnson \& Johnson, USA). The re-approximation of the rectus muscle in our clinic varies according to the preference of the surgeon. The rectus muscles were re-approximated using three loose vertical midline interrupted sutures with Vicryl 2.0 sutures (Ethicon Johnson \& Johnson, USA). Sutures are placed about $1 \mathrm{~cm}$ from the edge of the incision and $1 \mathrm{~cm}$ apart, without excessive tension. Subcutaneous fat is closed when the tissue was thicker than $2 \mathrm{~cm}$. The skin is reapproximated using a continuous subcuticular suture with 2.0 polypropylene (Ethicon Johnson \& Johnson, USA). All operative procedures are performed by the same surgeon.

\section{Statistical analysis}

Statistical analysis was performed using the Statistical Package for the Social Sciences (SPSS) version 21.0 software (IBM Corp., Armonk, NY, USA). The distribution of variables was tested for normality using histograms and the Shapiro-Wilk W-test. Parametric continuous data are presented as means \pm standard deviation, nonparametric continuous data are presented as medians (min-max), and categorical variables are expressed as numbers (percentages). Data 
Table 1. Characteristics of the 84 Postpartum Primiparous Women

\begin{tabular}{|c|c|c|c|c|}
\hline & & $\begin{array}{l}\text { Group } 1 \\
n=64\end{array}$ & $\begin{array}{l}\text { Group } 2 \\
n=64\end{array}$ & $\mathbf{P}$ \\
\hline Age (year & & $28.2 \pm 5.5$ & $26.9 \pm 4.7$ & 0.164 \\
\hline BMI & & $22.9 \pm 3.0$ & $22.5 \pm 2.8$ & 0.478 \\
\hline Gestation & & 38 (37-41) & $38(37-39)$ & 0.310 \\
\hline Fetal wei & & $3190 \pm 499$ & $3085 \pm 432$ & 0.203 \\
\hline Fetal sex & Female & 25 (39.7\%) & $38(60.3 \%)$ & ב2000 \\
\hline 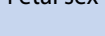 & Male & 39 (59.6\%) & 26 (41.2\%) & 0.022 \\
\hline
\end{tabular}

The data was calculated as $\mathrm{n}(\%)$, mean ( \pm standard deviation) and median (minimum-maximum). BMI — Body mass index; MP — Malpresentation; HT — Hypertension in pregnancy; FD - Fetal distress

Table 2. Comparison of ultrasonographic measurements of inter-rectus distances at the level of linea alba

\begin{tabular}{|l|l|l|l|}
\hline & $\begin{array}{l}\text { Group 1 } \\
\mathbf{n = 6 4}\end{array}$ & $\begin{array}{l}\text { Group 2 } \\
\mathbf{n = 6 4}\end{array}$ & $\mathbf{P}$ \\
\hline Width at xiphoid & $2.1 \pm 0.77$ & $2.2 \pm 0.62$ & 0.167 \\
\hline Thickness at xiphoid & $0.80 \pm 0.24$ & $0.84 \pm 0.18$ & 0.334 \\
\hline Width $3 \mathrm{~cm}$ above umbilicus & $2.41 \pm 0.83$ & $2.67 \pm 0.67$ & 0.056 \\
\hline Thickness $3 \mathrm{~cm}$ above umbilicus & $0.69 \pm 0.20$ & $0.75 \pm 0.21$ & 0.099 \\
\hline Width $2 \mathrm{~cm}$ below umbilicus & $2.16 \pm 0.82$ & $2.33 \pm 0.61$ & 0.210 \\
\hline Thickness $2 \mathrm{~cm}$ below umbilicus & $0.83 \pm 0.42$ & $0.79 \pm 0.17$ & 0.478 \\
\hline
\end{tabular}

The data was calculated as mean ( \pm standard deviation)

were analyzed using Student's t-test, Pearson's Chi-square test, Fisher's exact test, and the Mann-Whitney $U$ test. $\mathrm{p}<0.05$ was considered statistically significant.

The sample size for the research, calculations were made using $G^{*}$ Power 3.1.9.2 computer software [18]. The sample size was calculated using a fixed-effects single factor design of the t-test (independent sample t-test). Assuming $a=\% 5$, power $(1-\beta)=\% 80$, and an effect size $(d)=0.50$, a sample size of 64 cases in each arm was found to be required. One hundred twenty-eight patients were enrolled in each arm of the study protocol.

\section{RESULTS}

The demographic and ultrasonographic measurements of the patients are summarized in Table 1 and Table 2. There was a total of 128 patients, 64 in Group 1 and 64 in Group 2. All patients had CS under spinal anesthesia. Age, gestational week, fetal sex, and fetal birth weight were similar between the groups $(p>.05)$. The most frequent caesarean indication was malpresentation in both groups.

There were no statistically significant differences between the groups in terms of the distance between the rectus muscles and thickness of the rectus muscle at the described levels of xiphoid, umbilicus $3 \mathrm{~cm}$ above, and umbilicus $2 \mathrm{~cm}$ below ( $p>.05$ ).

\section{DISCUSSION}

CS is as one of the most frequently performed surgical procedures in the world, and the primary CS numbers have increased globally in recent times. There are many reasons for this stiuation: advanced maternal age, nulliparity, increased obesity, fear of pain during vaginal birth, concerns of genital changes after vaginal birth, idea of a more suitable method for both mother and healthcare professionals, and fear of legal issues due to delivery complications. Although it is one of the most common surgeries, there is no standard procedure for the whole operation, the search for a standard procedure continues. DRA is an important cosmetic problem that is frequently seen during pregnancy, in multiparous women, and after cesarean surgery $[11,14,17]$. Due to the risk for persisting of DRA in the postpartum period, it is important to take steps to prevent it during CS, especially at the rectus abdominis re-approxiamation step. In the literature, it has not been investigated whether there is a relationship between DRA and surgery interventions such as CS. Re-approximation of the rectus muscle can be considered as a reasonable intervention during $\mathrm{CS}$ in order to prevent DRA that increases as cesarean number increases. In our study it was found that the re-approximation of the rectus muscles during CS had no effect on DRA with ultrasonography performed in the first postoperative month. 
There are studies on the re-approximation of the rectus muscles during CS. Although short-term effects are mostly investigated in the literature, there are also studies investigating long-term results such as adhesions [10, 19] Lylel et al. [10] found that rectus muscle re-approximation increased immediate postoperative pain without differences in surgical time, surgical complications, or maternal satisfaction, and Omran et al. [19] found that rectus muscle re-approximation among women undergoing primary CS was associated with a significant increase in postoperative pain and analgesic requirements. In general, many physicians believe that re-approximation of the rectus muscles causes postoperative pain [20].

In our study, we investigated whether there was a relation between DRA - a condition that occurs physiologically during pregnancy and disappears after some time, but it persists in some women and causes cosmetic problems - and rectus muscle approximation in CS. For this reason, the distance between the rectus muscles in patients who had undergone primary CS was evaluated one month after the operation. In our study, the inter-rectus distances at all three anatomic regions were similar between the groups ( $p>.05)$.

DRA is a condition defined as an enlargement of the distance between the rectus muscles and occurs in the vast majority of pregnant patients. In a study conducted by Hsia et al. [21], the distance between the rectus muscles of women at 36 gestational weeks and at 12 gestational weeks was measured and the difference was observed to be $300-400 \%$. In another study, 84 healthy primiparous patients were followed up in terms of DRA for 35 gestational weeks and in postpartum periods from three different anatomic regions. In this study, the limit value for DRA was accepted as $16 \mathrm{~mm}$ at $2 \mathrm{~cm}$ below the umbilicus and all patients were diagnosed as having DRA at 35 weeks of gestation. However, this rate decreased to $35-39 \%$ in the ultrasonography examined at the 6 th postoperative month [22]. There is no clear consensus on DR distance. Some authors accept a direct $2 \mathrm{~cm}$ limit; however, DR distances have been found differently in some studies [11, 12, 23]. In some symptom-based studies, DRA symptoms were found to be at the margins of less than $2 \mathrm{~cm}$ [23]. In our study, we measured and compared direct distances because there was no clear cut-off value for DRA.

It has been shown that DRA is not just a cosmetic problem, it can also cause some clinical problems such as low back and pelvic girdle pain, urinary and anal incontinence, and pelvic organ prolapse [24-26]. However, there are conflicting results in the literature. A study by Spitznagle et al. [24] found that patients with DRA had at least one pelvic floor dysfunction, and there was a relationship between DRA and stress urinary incontinence, fecal incontinence, and pelvic organ prolapse. In a study by Parker et al. [25], it was found that abdominopelvic pain was significantly greater in women with DRA. In a systematic review of Benjamin et al. [26] on 2242 patients, no significant relationship was found between DRA and lumbopelvic pain, health-related quality of life, and incontinence.

The limitations of the study include the low sample size of patients, we only took primigravid patients; the inter-rectus distance is unknown during pregnancy; and some variables such as the exercise and muscle strength history of patients were not investigated. However, the strength of the study is the investigation of the relation between a frequent surgical procedure and a common clinical condition that has never been investigated before.

Reapproximation of rectus muscles has no effect on the prevention of DRA. However, there is a need for randomized controlled trials with large patient numbers where all variables are kept under control.

\section{Conflict of interest}

The authors declare that we have no conflicts of interest. No funding was received for this work.

\section{REFERENCES}

1. Boerma T, Ronsmans C, Boerma T, et al. Global epidemiology of use of and disparities in caesarean sections. Lancet. 2018; 392(10155): 1341-1348, doi: 10.1016/S0140-6736(18)31928-7, indexed in Pubmed: 30322584.

2. Santas G, Santas F. Trends of caesarean section rates in Turkey. J Obstet Gynaecol. 2018; 38(5): 658-662, doi: 10.1080/01443615.2017.1400525, indexed in Pubmed: 29519178.

3. Inal ZO, Inal HA, Kucukkendirci H, et al. Investigation of cesarean sections at Konya Training and Research Hospital Obstetrics and Gynecology Department between 2010 and 2015. Ginekol Pol. 2017; 88(4): 185-190, doi: 10.5603/GP.a2017.0036, indexed in Pubmed: 28509319.

4. Encarnacion B, Zlatnik MG. Cesarean delivery technique: evidence or tradition? A review of the evidence-based cesarean delivery. Obstet Gynecol Surv. 2012; 67(8): 483-494, doi: 10.1097/OGX.0b013e318267699f, indexed in Pubmed: 22926273.

5. Popov I, Stoĭkov S, Bakŭrdzhiev G, et al. A single-stage 2-layer suture in cesarean section--the effect of the surgical technic on postoperative febrile conditions. Akush Ginekol (Sofiia). 1994; 33(2): 13-15, indexed in Pubmed: 7485768.

6. Katsulov A, lankov M, Bobchev T. A surgical technic for cesarean section and gynecological laparotomy without suturing of the parietal and visceral peritoneum and the single-layer suturing of the uterus during the section (a review of the literature and initial experience). Akush Ginekol (Sofiia). 1998; 37(4): 40-46, indexed in Pubmed: 10360054.

7. Bamigboye AA, Hofmeyr GJ. Closure versus non-closure of the peritoneum at caesarean section: short- and long-term outcomes. Cochrane Database Syst Rev. 2014(8): CD000163, doi: 10.1002/14651858. CD000163.pub2, indexed in Pubmed: 25110856.

8. Cheong YC, Premkumar G, Metwally $M$, et al. To close or not to close? A systematic review and a meta-analysis of peritoneal non-closure and adhesion formation after caesarean section. Eur J Obstet Gynecol Reprod Biol. 2009; 147(1): 3-8, doi: 10.1016/j.ejogrb.2009.06.003, indexed in Pubmed: 19596507.

9. Kapustian V, Anteby EY, Gdalevich M, et al. Effect of closure versus nonclosure of peritoneum at cesarean section on adhesions: a prospective randomized study. Am J Obstet Gynecol. 2012; 206(1): 56.e1-56.e4, doi: 10.1016/j.ajog.2011.07.032, indexed in Pubmed: 21924397.

10. Lyell DJ, Naqvi M, Wong A, et al. Rectus Muscle Reapproximation at Cesarean Delivery and Postoperative Pain: A Randomized Controlled Trial. Surg J (N Y). 2017; 3(3): e128-e133, doi: 10.1055/s-0037-1604074, indexed in Pubmed: 28840194. 
11. Akram J, Matzen SH. Rectus abdominis diastasis. J Plast Surg Hand Surg. 2014; 48(3): 163-169, doi: 10.3109/2000656X.2013.859145, indexed in Pubmed: 24256310.

12. Beer GM, Schuster A, Seifert B, et al. The normal width of the linea alba in nulliparous women. Clin Anat. 2009; 22(6): 706-711, doi: 10.1002/ca.20836, indexed in Pubmed: 19637295.

13. Candido G, Lo T, Janssen P. Risk factors for diastasis of the recti abdominis. J Assoc Chart Physiother Womens Health. 2005; 97: 49.

14. Turan V, Colluoglu C, Turkyilmaz E, et al. Prevalence of diastasis recti abdominis in the population of young multiparous adults in Turkey. Ginekol Pol. 2011; 82(11): 817-821, indexed in Pubmed: 22384613.

15. Rath AM, Attali P, Dumas JL, et al. The abdominal linea alba: an anatomo-radiologic and biomechanical study. Surg Radiol Anat. 1996; 18(4): 281-288, doi: 10.1007/BF01627606, indexed in Pubmed: 8983107.

16. Nahas F. An Aesthetic Classification of the Abdomen Based on the Myoaponeurotic Layer. Plastic and Reconstructive Surgery. 2001; 108(6): 1787-1795, doi: 10.1097/00006534-200111000-00058.

17. Coldron Y, Stokes MJ, Newham DiJ, et al. Postpartum characteristics of rectus abdominis on ultrasound imaging. Man Ther. 2008; 13(2): 112121, doi: 10.1016/j.math.2006.10.001, indexed in Pubmed: 17208034.

18. Faul F, Erdfelder E, Lang AG, et al. G*Power 3: a flexible statistical power analysis program for the social, behavioral, and biomedical sciences. Behav Res Methods. 2007; 39(2): 175-191, doi: 10.3758/bf03193146, indexed in Pubmed: 17695343.

19. Omran EF, Meshaal H, Hassan SM, et al. The effect of rectus muscle re-approximation at cesarean delivery on pain perceived after operation: a randomized control trial. J Matern Fetal Neonatal Med. 2019; 32(19): 3238-3243, doi: 10.1080/14767058.2018.1461829, indexed in Pubmed: 29618226.
20. Dahlke JD, Mendez-Figueroa $\mathrm{H}$, Rouse DJ, et al. Evidence-based surgery for cesarean delivery: an updated systematic review. Am J Obstet Gynecol. 2013; 209(4): 294-306, doi: 10.1016/j.ajog.2013.02.043, indexed in Pubmed: 23467047.

21. Hsia M, Jones $S$. Natural resolution of rectus abdominis diastasis. Two single case studies. Aust J Physiother. 2000; 46(4): 301-307, doi: 10.1016/s0004-9514(14)60291-9, indexed in Pubmed: 11676815.

22. Fernandes da Mota PG, Pascoal AG, Carita Al, et al. Prevalence and risk factors of diastasis recti abdominis from late pregnancy to 6 months postpartum, and relationship with lumbo-pelvic pain. Man Ther. 2015; 20(1): 200-205, doi: 10.1016/j.math.2014.09.002, indexed in Pubmed: 25282439.

23. Keshwani N, Mathur S, McLean L. Relationship Between Interrectus Distance and Symptom Severity in Women With Diastasis Recti Abdominis in the Early Postpartum Period. Phys Ther. 2018; 98(3): 182-190, doi: 10.1093/ptj/pzx117, indexed in Pubmed: 29228344.

24. Spitznagle TM, Leong FC, Van Dillen LR. Prevalence of diastasis recti abdominis in a urogynecological patient population. Int Urogynecol J Pelvic Floor Dysfunct. 2007; 18(3): 321-328, doi: 10.1007/s00192-0060143-5, indexed in Pubmed: 16868659.

25. Parker M, Millar L, Dugan S. Diastasis Rectus Abdominis and Lumbo-Pelvic Pain and Dysfunction-Are They Related? Journal of Women's Health Physical Therapy. 2009; 33(2): 15-22, doi: 10.1097/01274882200933020-00003.

26. Benjamin DR, Frawley HC, Shields N, et al. Relationship between diastasis of the rectus abdominis muscle (DRAM) and musculoskeletal dysfunctions, pain and quality of life: a systematic review. Physiotherapy. 2019; 105(1): 24-34, doi: 10.1016/j.physio.2018.07.002, indexed in Pubmed: 30217494. 